\title{
EVOLUTIONARY MULTI-OBJECTIVE WEATHER ROUTING OF SAILBOATS
}

\author{
Ewa Sobecka \\ Rafał Szłapczyński \\ Marcin Życzkowski \\ Gdańsk University of Technology, Poland
}

\begin{abstract}
The paper presents a multi-objective method, which optimises the route of a sailboat. The presented method makes use of an evolutionary multi-objective (EMO) algorithm, which performs the optimisation according to three objective functions: total passage time, a sum of all course alterations made during the voyage and the average angle of heel. The last two of the objective functions reflect the navigator's and passenger's comfort, which may decrease with multiple turns or when experiencing an excessive heel angle for a long time. The optimisation process takes into account static bathymetry-related constraints as well as dynamic constraints related to the sailboat's safety in changing wind and wave conditions. The method makes use of all of the above and finally returns an approximated Pareto set containing non-dominated solutions to the optimisation problem. The developed method has been implemented as a simulation application. The paper includes selected simulation results followed by their discussion.
\end{abstract}

Keywords: sailing vessels, weather routing, evolutionary multi-objective optimization, weather forecasts, navigation

\section{INTRODUCTION}

WWeather routing is planning a ship's route including weather conditions, which are essential to the navigability of the sailing vessel. Choosing the right route affects not only the travel time, but also its safety, as well as the comfort of passengers and crew. The weather's impact is particularly large in the case of sailboats. Adverse wind conditions may greatly increase the passage time. They may also result in excessive heel angles, thus causing major discomfort for people on board or even compromising the sailboat's safety. The paper addresses this problem by proposing a multi-objective sailboat weather routing optimisation method. The method applies an improved Strength Pareto Evolutionary Algorithm (SPEA 2) [1], which performs the optimisation according to three objective functions: total passage time, the sum of all course alterations made during the voyage and the average angle of heel. Instead of aggregating these objectives into one, the algorithm searches for a Pareto-optimal set containing all non-dominated solutions. The number of non-dominated solutions may vary depending on the circumstances and in some cases it may be too large, making it hard for the navigator to choose one route to follow. Therefore a preference-based approach called $\mathrm{r}$-dominance [2] is additionally applied here. The navigator can specify a reference solution as a point in the 3-dimensional objective space. The specified point represents desired or acceptable values of all objectives. Owing to this, the optimisation method is able to focus on solutions reflecting the navigator's preferences, which results in a shorter processing time, better approximation of the true Pareto set and a limited set of final solutions to choose from. The method has been implemented as a software tool. Following this, a series of computer simulations have been carried out. Their results confirm the method's effectiveness (given by the quality of the recommended routes) and efficiency (acceptable computational time for all scenarios). The rest of the paper is organised as follows. Section 2 presents current research in the field of weather routing and points out limitations of 
the various approaches applied. Section 3 describes weather routing as an optimisation problem. Section 4 describes the proposed weather routing optimisation method, which solves this problem. Following this, Section 5 contains the results of the simulations carried out using the proposed method. Finally, the summary and conclusions are presented in Section 6.

\section{RELATED WORKS}

Published works on weather routing of sailboats are relatively few; however, the discussed problem is closely related to weather routing of merchant ships, which has been widely researched. Nowadays, in maritime shipping, a travel plan is required by the International Convention for the Safety of Life at Sea (SOLAS) and requires planning of the route before starting a sea journey [3]. Route planning applies to all vessels, including sailing ones. Route planning depends on the user's requirements, including the need to perform the tasks and taking into account the restrictions arising from the existing conditions in the area of navigation. There are different approaches to developing route planning methods for vessels, and the methods that are being used can be divided into two groups: deterministic and non-deterministic. The first are methods that repeatedly return the same solution for the same input data. Updating the input data or changing the method itself can lead to returning a different solution. The second group are non-deterministic methods, which are usually applied in situations when deterministic solutions would be too time-consuming.

In deterministic methods we can distinguish isochron methods [4, 5], dynamic methods [6-9] as well as those rooted in a graph theory. The isochron method is based on the analysis of meteorological forecasts, and knowing the speed characteristics of the ship it is possible to manually determine the minimum time path. In dynamic methods, the next $\mathrm{P}_{i}$ position, with the $S_{i}$ state, depends directly on the $S_{i+1}$ state. As for graph-oriented methods, when all possible waypoints are defined and the possible flows between them are known, one can implement routing as determining the optimal path in the graph. Examples include methods using the modified Dijkstra algorithm [10-15] or the A *algorithm [16, 17].

Non-deterministic methods may include genetic and evolutionary methods, methods based on distributed intelligence, and others. Both genetic and evolutionary methods [18-21] are based on the heuristic algorithm for finding solutions according to natural selection. As this group is based on distributed intelligence [22-24] their idea is derived from imitating the behaviour of living beings (e.g. ants, bees or wolves). Other examples of non-deterministic routing methods include rapid walking [25].

Routing methods differ greatly in their range of use and include transoceanic routing based on long-term weather forecasts as well as relatively short-distance planning, which may take into account local weather data $[26,27]$ downloaded on route by means of a wireless network [28]. The common feature of most of the above methods is that they rely on single-objective optimisation. Exceptions are few and concern solely the routing of merchant vessels [22, 23, 29]. As for methods dedicated to sailboats, up till now they have applied multiple objectives by means of a single aggregated goal function $[13,14]$. Such an approach is seriously limiting because it excludes many potential solutions, which cannot be obtained this way. The current paper aims to fill this gap by offering a truly multi-objective method of weather routing for sailboats.

\section{SAILBOAT WEATHER ROUTING AS A MULTI-OBJECTIVE OPTIMISATION PROBLEM}

In the considered problem, a vector of three objective functions $F(x)$ (1) is subject to optimisation. The vector consists of the total passage time, $f_{\text {time }}(2)$, the sum of direction changes $f_{\text {chdir }}(3)$ within a route and the weighted average of heel angles $f_{\text {heel }}(4)$ computed over all route segments.

$$
\begin{array}{r}
F(x)=\left[f_{\text {time }}, f_{\text {chdir }}, f_{\text {heel }}\right] \\
f_{\text {time }}=\sum_{i=1}^{n} \frac{s_{i}}{V_{i}} \rightarrow \text { min } \\
f_{\text {chdir }}=\sum_{k=1}^{n-1} \Delta \alpha_{k, k+1} \rightarrow \text { min } \\
f_{\text {heel }}=\frac{\sum_{i=1}^{n} \varphi_{i} * t_{i}}{t} \rightarrow \text { min }
\end{array}
$$

where:

$s_{i} \quad$ - distance covered by the sailboat on the $i$-th segment of a route,

$$
s_{i}=\sqrt{\left(x_{i}-x_{i+1}\right)+\left(y_{i}-y_{i+1}\right)}
$$

$V_{i} \quad$ - sailboat's speed on the $i$-th segment of a route (between points $k$ and $k+1$ )

$$
V\left(P_{k}, P_{k+1}\right)=\gamma\left({\overrightarrow{W_{k}}}_{i, i+1}\right)=\gamma\left(w_{k}, \beta_{i, i+1}\right)
$$

where:

$$
\begin{aligned}
& \alpha_{i, i+1} \quad-\text { direction from point } P_{k} \text { to } P_{k+1} \\
& \beta_{i, i+1}^{i, i+1} \quad \text { - angle between the sailboat's course and true } \\
& \text { wind direction } \\
& w_{k} \quad-\text { wind speed } \\
& \gamma\left(w_{k}, \beta_{i, i+1}\right) \text { - sailboat's speed calculated on the basis of the } \\
& \text { polar diagram for a given wind speed } w_{k} \text { and } \\
& \text { direction } \beta_{i, i+1} \\
& \text { - tilt on the } i \text {-th segment of a route [rhumb] } \\
& \text { - time to complete the } i \text {-th segment of a route [h] } \\
& \text { - time to cover the entire route, } t=\sum_{i=1}^{n} t_{i}[\mathrm{~h}] \text {. }
\end{aligned}
$$

The control variables of each route are geographical coordinates of route waypoints - a sequence of latitude and longitude values. 
The goal is to minimise simultaneously all three objective functions, while making sure that the solutions are acceptable in terms of meeting the constraints. The choice of objective functions is supposed to reflect the practical needs of various potential decision makers. As for the heel angle, it reflects both the passenger's safety and comfort, though other objectives are possible here, namely roll velocity or roll acceleration, as mentioned in [30]. In general, the three objective functions may be contradictory; for example, smooth routes usually take more time. Therefore in practice the result of the optimisation process is not one route but a set of Pareto-optimal routes, where each route within the set is defined by a sequence of waypoints - pairs of latitude and longitude geographical coordinates.

A solution is acceptable if the following constraints are met throughout the route:

- the ship's safety isobath is not violated,

- the heel angle does not exceed a maximum acceptable value (defined by the user),

- the wind's speed does not exceed a maximum acceptable value (defined by the user).

The optimisation problem given above can be approached in a number of ways, applying both deterministic and indeterministic methods mentioned in the section on related works. Deterministic approaches include the multi-objective Dijkstra algorithm, multi-objective dynamic programming and multi-objective linear convolution of the functional. Their huge advantage is that, given enough time, they always converge to the optimal solution set. However, considering the complexity of map-derived constraints, deterministic approaches are not always acceptable in terms of timeefficiency, as their computational time rises with the size of the map and number of waypoints, as observed in [31]. Therefore, an indeterministic approach has been chosen here, namely, one of evolutionary multi-objective optimisation algorithms (EMO). Details are provided in the following section.

\section{THE PROPOSED METHOD OF WEATHER ROUTING}

In this section the proposed method is described in detail, covering the applied multi-objective evolutionary algorithm SPEA2 (The Applied Algorithm section),

\section{THE APPLIED ALGORITHM}

The proposed method uses an evolutionary multi-objective (EMO) algorithm to solve the problem. EMO algorithms belong to multi-objective metaheuristics (MOMH), whose common feature is that they search for a Pareto-optimal set containing all non-dominated solutions to a problem. For minimisation of all objectives, a solution $y$ is non-dominated if there is no other solution $x$ in the set, for which the following dominance relation would hold true:

$\mathrm{G}_{i}\left(f_{i}(x)<f_{i}(y)\right)$ and $\mathrm{V}_{i}\left(f_{i}(x) \leq f_{i}(y)\right)$, where $f_{i}(x), f_{i}(y)$ are the values of the $i$-th objective for solutions $x$ and $y$.
It is worth mentioning that an acceptable solution (one that meets the constraints) always dominates an unacceptable one, even if the latter has better (here - lower) values of all objectives.

What distinguishes EMO algorithms from other MOMH approaches is that they implement mechanisms similar to those observed during evolution in nature. Randomly generated individuals are subject to mutation and crossbreeding processes, creating a new population of individuals in which units with a higher adaptation rate have greater chances of survival and extension, according to pre-set criteria. In general, the operation of each evolutionary algorithm is based on a loop, which is formed successively by reproduction, genetic operations, evaluation and succession. It is visualised in Fig. 1.

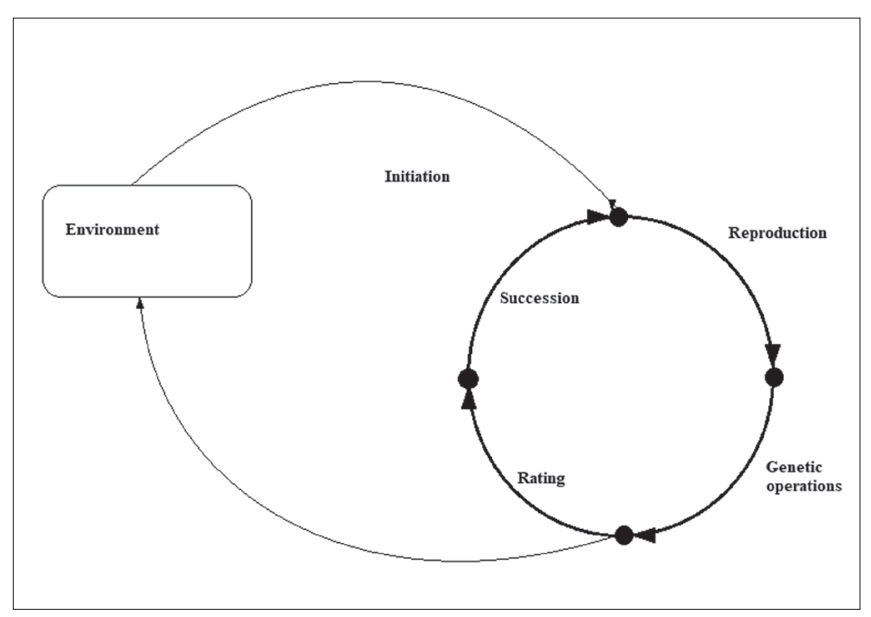

Fig. 1. The loop of operations in an evolutionary algorithm framework

From among many algorithms of evolutionary multiobjective optimisation, the improved Strength Pareto Evolutionary Algorithm (SPEA2) was selected to solve the problem specified in Section 3. SPEA2 extends the classic evolutionary approach from Fig. 1; here the main algorithm loop consists of the following elements:

- Initialisation - the initial base population and empty archive are generated at this stage.

- Fitness assignment - fitness values are calculated for all individuals.

- Environmental selection - all non-dominated individuals are copied to the next population.

- Termination - if any of the end conditions are met at this stage, the loop should be stopped.

- Mating selection - followed by a binary tournament selection of parents, who will reproduce.

- Variation - recombination and mutation takes place, a new generation follows, the future population becomes present, go to Fitness assignment.

As for initialisation, the base population includes: orthodrome and loxodrome routes (including their random variations) as well as purely random routes. There is no guarantee that any route from the initial population is acceptable; however, they are systematically improved by the process in the course of subsequent generations, which is given in Fig. 2. 


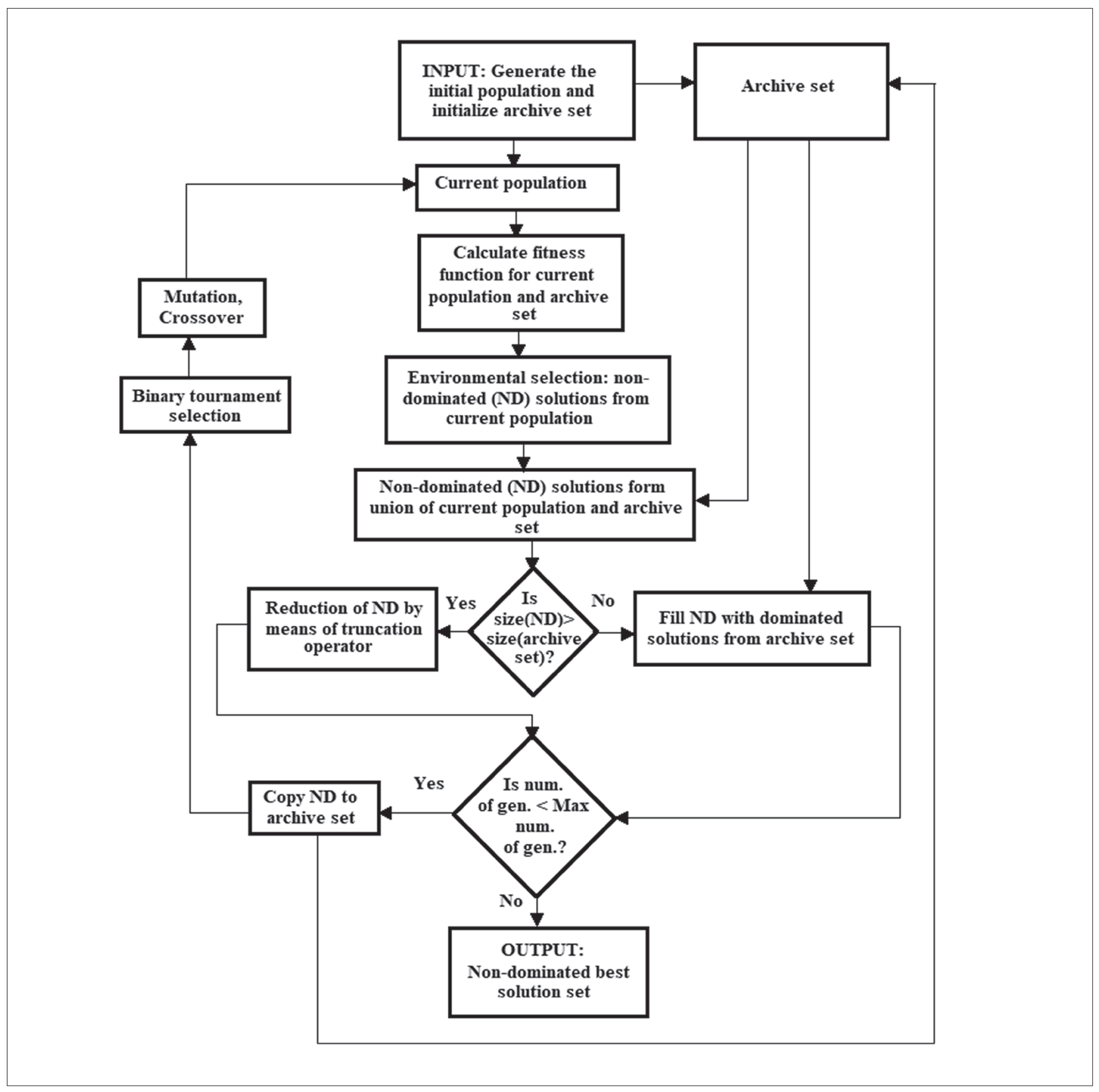

Fig. 2. SPEA2 algorithm framework

\section{SELECTED PREFERENCE-BASED APPROACH}

A popular approach in Multi-Objective Meta- Heuristics $(\mathrm{MOMH})$ is to take into account user preferences, whereby the algorithm may focus on the part of the objective space that is most interesting to the user. Among others, limiting the objective space results in reduction of the Pareto front and thus in a faster convergence of the algorithm. Making use of the preferences can be done in a number of ways [32]. A common one is that of a reference point (RP) - a point in the objective space, which represents a solution that is desired and seems possible to reach by the method [33-35]. An RP may be directly used for dominance relation $[2,36]$, thus extending strict Pareto dominance. Of various RP-based methods, r-dominance [2] is particularly successful and flexible and has therefore been chosen to be applied here.

The r-dominance mechanism works as follows. First a user specifies a reference point (RP) - the desired values of all objective functions. The task of the algorithm is then to strive to reach final values as close to the set values as possible while maintaining dominance in the Pareto sense.

This means that non-dominated solutions that have a smaller distance from the RP in the space of optimal solutions will be rated better than non-dominated solutions at a larger distance from the RP. This distance is expressed by the following formula (5): 


$$
\begin{gathered}
\operatorname{Dist}(x, g)=\sqrt{\sum_{i=1}^{M} w_{i}\left(\frac{f_{f}(x)-f_{f}(g)}{f_{i}^{\prime n x x}-f_{i}^{\prime \prime m}}\right)^{2}} \\
\left.w_{i} \in\right] 0,1\left[\sum_{i=1}^{M} w_{i}=1\right.
\end{gathered}
$$

where:

$\operatorname{Dist}(x, g)$ - weighted Euclidean distance between point $x$ and $g$,

$x-$ a solution that is considered,

$g \quad-$ reference point with i coordinates,

$f_{i}^{\max }$ - upper limit of the value of the $i$-th goal function,

$f_{i}^{\min } \quad-$ lower limit of the value of the $i$-th goal function,

$w_{i} \quad$ - weight assigned to the $i$-th goal function.

\section{APPLYING THE ALGORITHM TO SOLVE THE OPTIMISATION PROBLEM}

In order to apply the algorithms, apart from algorithm implementation, two kinds of mechanisms have to be prepared first:

- checking if all constraints are met (including safe distance from landmasses, acceptable heel angle and acceptable wind speed),

- determining objective functions values.

Of all the constraints, checking the geographical ones is most time-consuming. First, an electronic navigational chart has been converted to a bitmap to make use of the bathymetric data [37]. Following this, information on whether a map cell is passable or not can be read directly from a bitmap. Consequently, it is possible to check if a route segment does not cross any landmass or safety isobaths. It is assumed that the route must be at least one bitmap cell away from the safety isobath. As for the other constraints, wind speed is read directly from a saved weather forecast file, while the heel angle is read from the sailboat's polar diagram provided for a particular combination of wind speed and relative angle between the sailboat's course and the true wind direction.

The detailed values of constraint thresholds assumed for simulations are as follows:

- maximal acceptable angle of heel - 30 degrees,

- minimal acceptable distance from safety isobath - the size of a bitmap cell: $0.17 \mathrm{NM}(315 \mathrm{~m})$.

The sailboat's speed can be read directly from the provided diagram of velocity polar prediction (VPP) [14]. Knowing the sailboat's speed and heel angle for all the sampled combinations of wind conditions and sailboat courses, all the objective function values can be computed for each segment of the route. Having done this, each objective value is aggregated over all route segments and the final objective values are obtained.

\section{SIMULATION RESULTS}

In this section examples of simulation results are provided and discussed. Brief descriptions of all scenarios, followed by their detailed results, are given in the next four subsections. This is followed by a discussion of the results.

Throughout all the scenarios the same sailboat was used, whose parameters are presented in Table 1, with the polar diagram given in Fig. 3 .

Tab. 1. CONRAD 1200 RT - sailing vessel details

\begin{tabular}{|c|c|c|}
\hline Parameter & Value & {[]} \\
\hline Volume (displaced) & 8.450 & $\mathrm{~m}^{3}$ \\
\hline Draft amidships & 2.0 & $\mathrm{~m}$ \\
\hline WL length & 12.00 & $\mathrm{~m}$ \\
\hline Beam max extents on WL & 3.1 & $\mathrm{~m}$ \\
\hline Sail area & 80 & $\mathrm{~m}^{2}$ \\
\hline
\end{tabular}

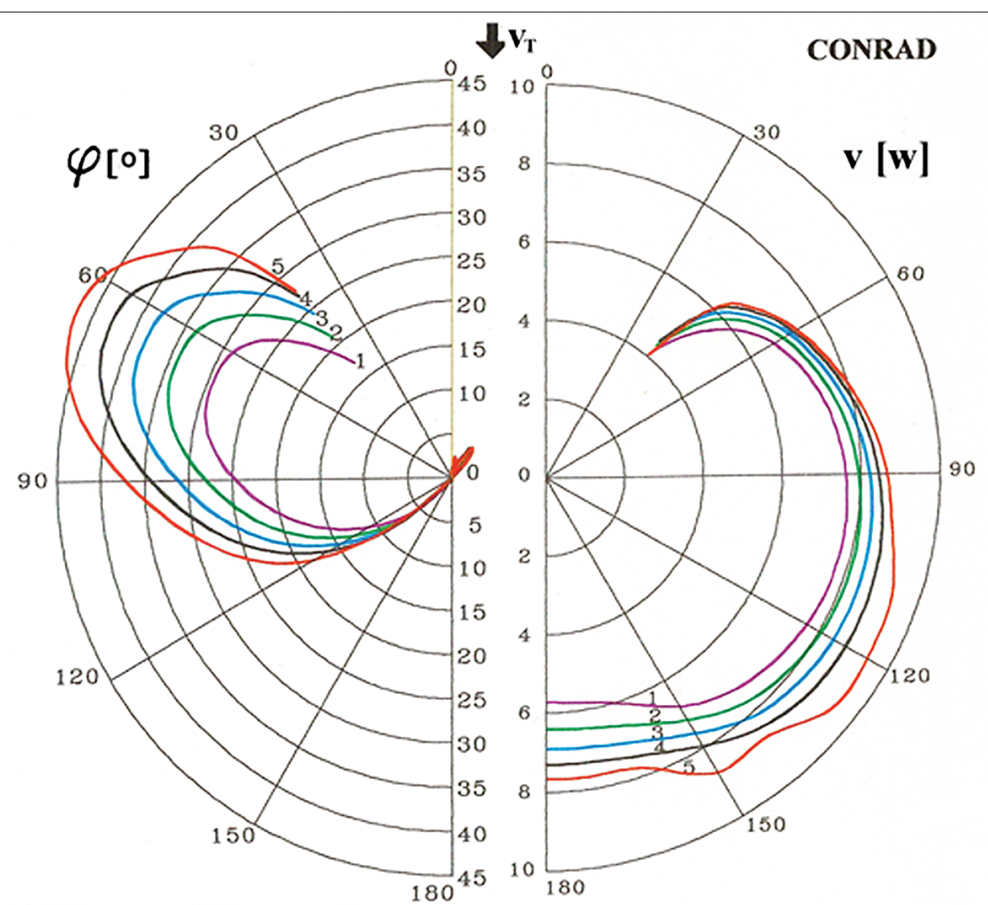

Fig. 3. A polar diagram of VPP and angle of heel, source [34]. True wind speed: $1-12 \mathrm{kt}, 2-14 \mathrm{kt}, 3-16 \mathrm{kt}, 4-18 \mathrm{kt}, 5-20 \mathrm{kt}$ 
Tab. 2. Input data for all four scenarios

\begin{tabular}{|c|c|c|c|c|c|}
\hline \multirow{2}{*}{ Scenario } & From & \multirow{2}{*}{ To } & \multirow{2}{*}{$\begin{array}{c}\text { Number of } \\
\text { objectives }\end{array}$} & \multicolumn{2}{|c|}{ Wind directions and speeds for subsequent periods of travel [m/s] / [kt] } \\
\cline { 4 - 6 } & & & 1 & 3 \\
\hline 1 & Gulf of Gdańsk & Świnoujście & 2 & $5.12 / 10 \mathrm{NE}$ & $6.6 / 12.8 \mathrm{NE}$ \\
\hline 2 & Gulf of Gdańsk & Świnoujście & 3 & $5.12 / 10 \mathrm{NE}$ & $6.6 / 12.8 \mathrm{NE}$ \\
\hline 3 & Świnoujście & Gulf of Gdańsk & 3 & $5.12 / 10 \mathrm{NE}$ & $6.6 / 12.8 \mathrm{NE}$ \\
\hline 4 & Świnoujście & Gulf of Gdańsk & 3 & $13 / 25.3 \mathrm{NE}$ & $11.5 \mathrm{NE}$ \\
\hline
\end{tabular}

The following parameter values are used there: true wind speed Vr: 1 - 12 knots, 2 -

14 knots, 3 - 16 knots, 4 - 18 knots, 5 - 20 knots. $\rightarrow-$ true wind direction with velocity $v_{T}[\mathrm{w}], \gamma$ - heading angle of vessel $\left[{ }^{0}\right], v$ - speed forecast of vessel: $v=v\left(v_{T}, \gamma\right)$.

Additional data for all four scenarios is presented in Table 2, where the travel direction, wind conditions (direction and speed) and applied objective functions are given. Finally, the SPEA 2 and $r$-dominance settings are given in Table 3.

Tab. 3. SPEA2 and r-dominance settings

\begin{tabular}{|c|c|c|c|}
\hline Parameter & $\begin{array}{c}\text { Time } \\
\text { [hours] }\end{array}$ & $\begin{array}{c}\text { Total } \\
\text { direction } \\
\text { changes }\end{array}$ & $\begin{array}{c}\text { Angle } \\
\text { of heel } \\
\text { [degrees] }\end{array}$ \\
\hline Reference point coordinates & 30 & 20 & 15 \\
\hline $\begin{array}{c}\text { Weights for 2- objective } \\
\text { case (Scenario 1) }\end{array}$ & 0,7 & - & 0,3 \\
\hline $\begin{array}{c}\text { Weights for 3- objective } \\
\text { cases (Scenarios 2, 3 and 4) }\end{array}$ & 0,6 & 0,2 & 0,2 \\
\hline
\end{tabular}

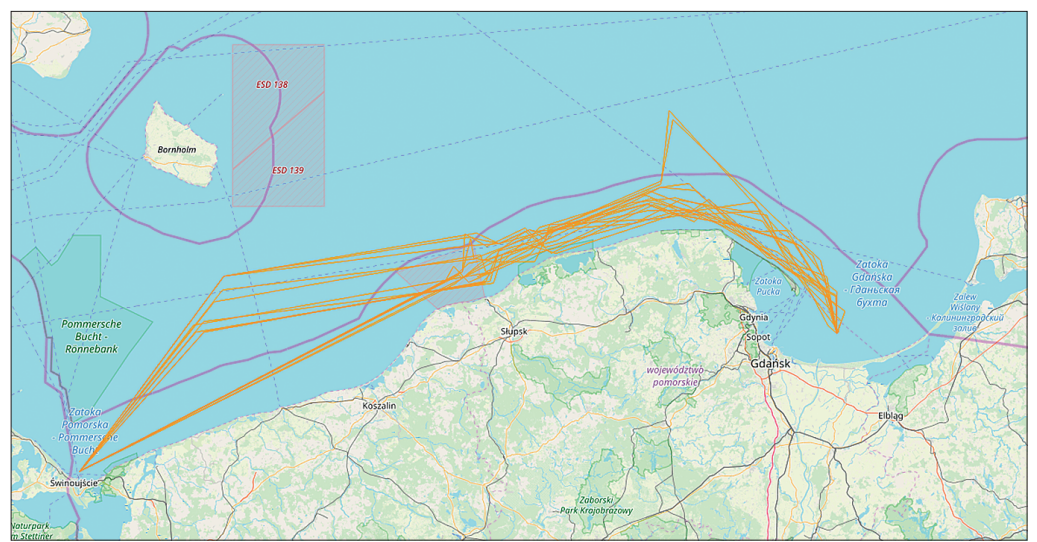

Fig. 4. Routes found in Scenario 1

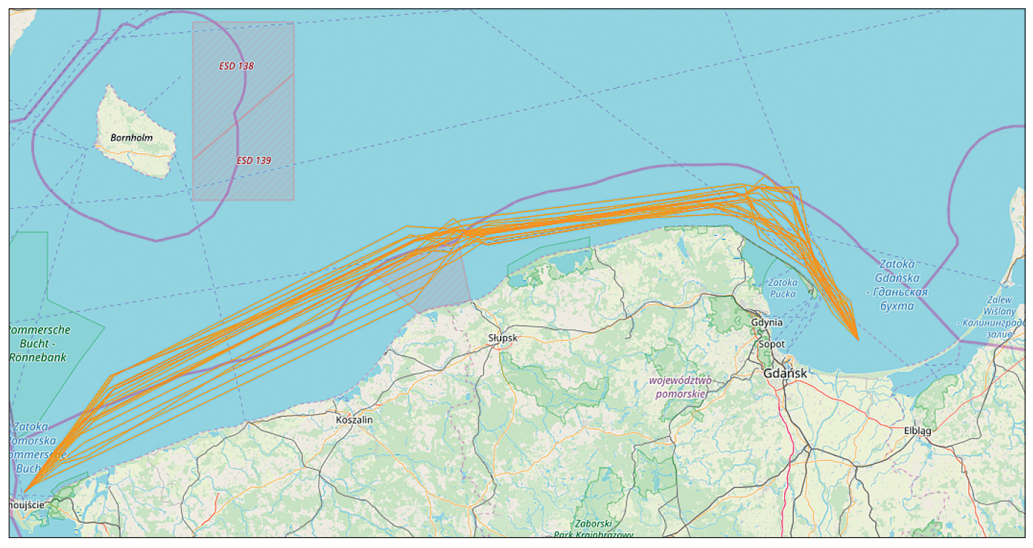

Fig. 6. Routes found in Scenario 2.

\section{SCENARIO 1}

Scenario 1 involves finding a route from the Gulf of Gdańsk to Świnoujście in mild weather conditions for two optimisation objectives: total passage time and average angle of heel. The resulting set of solutions approximating true Pareto-optimal routes is shown in Fig. 4. Objective values of all selected routes are visualised in the 2-dimensional objective space in Fig. 5.

\section{SCENARIO 2}

Scenario 2 involves finding a route from the Gulf of Gdańsk to Świnoujście in the same weather conditions as scenario 1, but this time for three optimisation objectives: total passage time, average angle of heel and the sum of all direction changes. The resulting set of solutions approximating true Pareto-optimal routes is shown in Fig. 6. Objective values of all selected routes are visualised in a 3-dimensional objective space in Fig. 7.

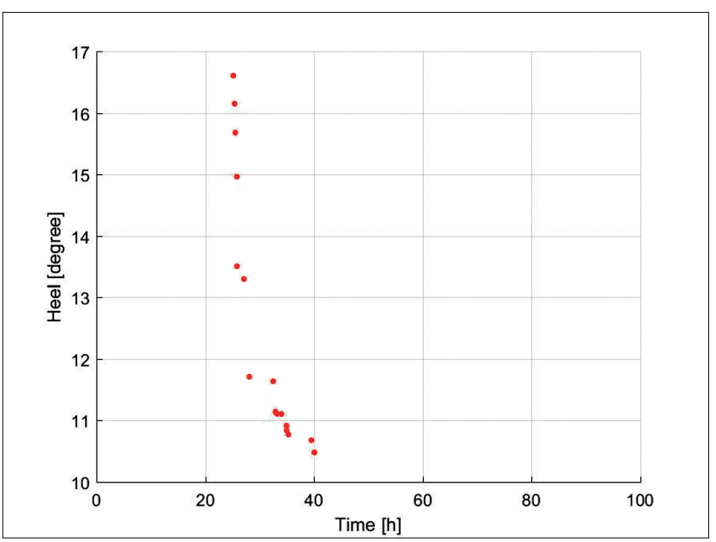

Fig. 5. Objective values of routes found in Scenario 1

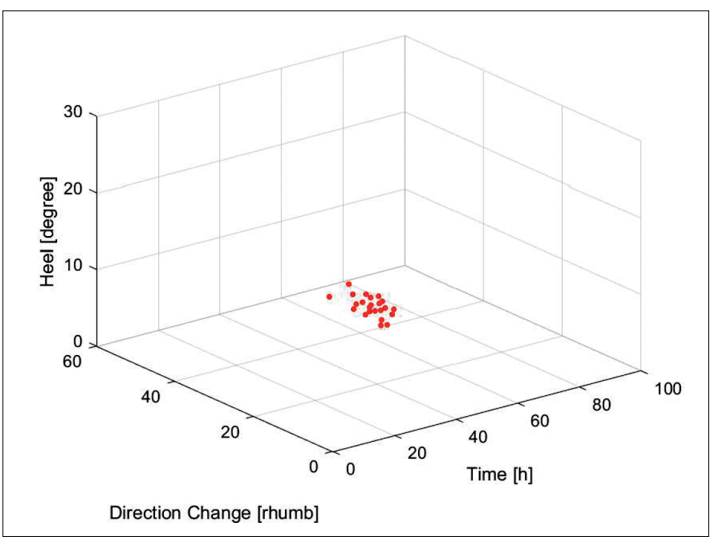

Fig. 7. Objective values of routes found in Scenario 2 
As can be seen, the addition of a third goal function, the one minimising the sum of course changes, has smoothed the route shape. Previously, when only voyage times and average angle of heel were minimised, frequent multiple turns were visible (Fig. 4). Their purpose was to increase the sailboat's speed on a given segment of a route by making the best use of the wind. Such policy made the total time shorter but the routes would be harder to follow, especially for a less experienced sailor. Now, after incorporating the third objective, the routes are now less diverse, much closer to each other and easier to follow, as they do not include so many turns. However, the smoothness of the routes is obtained at the cost of a much longer voyage time - it grows from 30-40 hours (Scenario 1) to over 60 (Scenario 2). Smoother routes also result in a much smaller average angle of heel. The latter can be attributed to very sharp heel angle curves in the left part of Fig. 3. Namely, a small change in the relative angle to the wind may cause a significant difference in the heel angle.

\section{SCENARIO 3}

Scenario 3 involves finding a route back from Świnoujście to the Gulf of Gdańsk for all three optimisation objectives. The resulting set of solutions approximating true Pareto-optimal routes is shown in Fig. 8. Objective values of all selected routes are visualised in a 3-dimensional objective space in Fig. 9. As can be seen, the routes have different shapes from those in Scenario 2. Because of sailing in the opposite direction, the sailboat faces different wind conditions, which results in different turns made to minimise the objective values.

\section{SCENARIO 4}

Scenario 4 again involves finding a route from Świnoujście to the Gulf of Gdańsk for all three optimisation objectives. This time, however, the sailing conditions are much harder due to a very strong wind. The resulting set of solutions approximating true Pareto-optimal routes is shown in Fig. 10. Objective values of all selected routes are visualised in a 3-dimensional objective space in Fig. 11. The strong wind seriously limits the manoeuvring possibilities of the sailboat - not all courses are taken into account, as some of them would result in excessive heel angles (larger than the assumed limit of 30 degrees). This limitation translates to a much smaller choice of acceptable solutions, which in turn limits the final set of Pareto-optimal routes, with fewer optimal routes. However, all of the returned Pareto-optimal routes are very good in terms of objective values. Strong wind makes it possible to achieve a greater speed and thus reduces the travel time. The shapes of the routes are smoother, with a smaller number of turns. Multiple turns are avoided because they could lead to a much larger sum of direction changes, lower average speed and larger angle of heel for some of the route segments. In contrast, smooth routes make it possible to avoid the latter, thus achieving a successful minimisation of all objectives simultaneously.

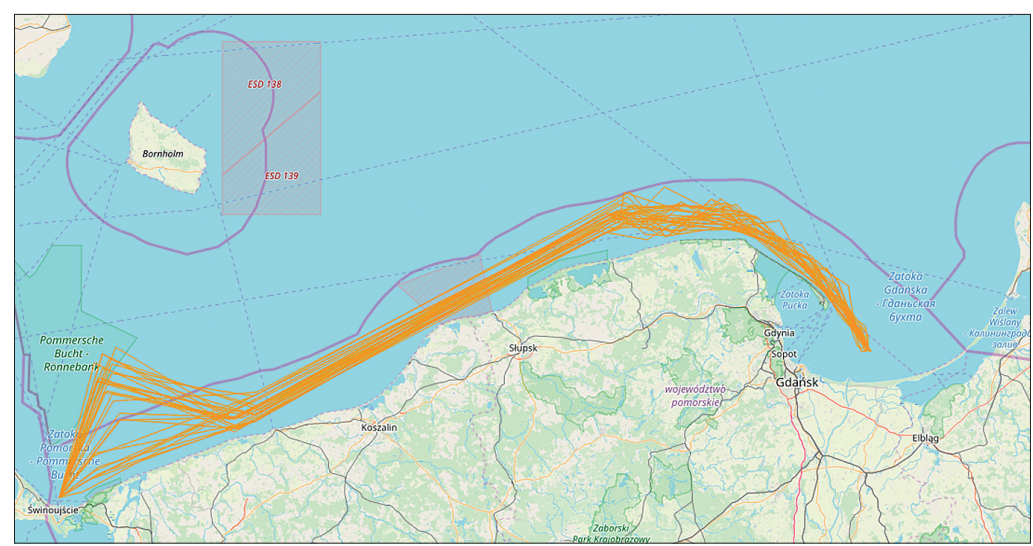

Fig. 8. Routes found in Scenario 3.

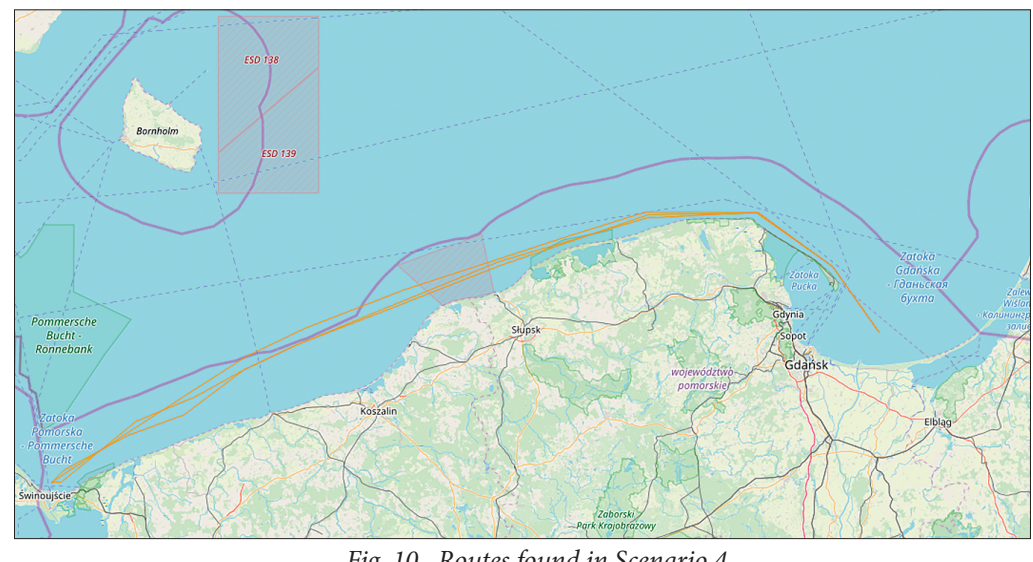

Fig. 10. Routes found in Scenario 4

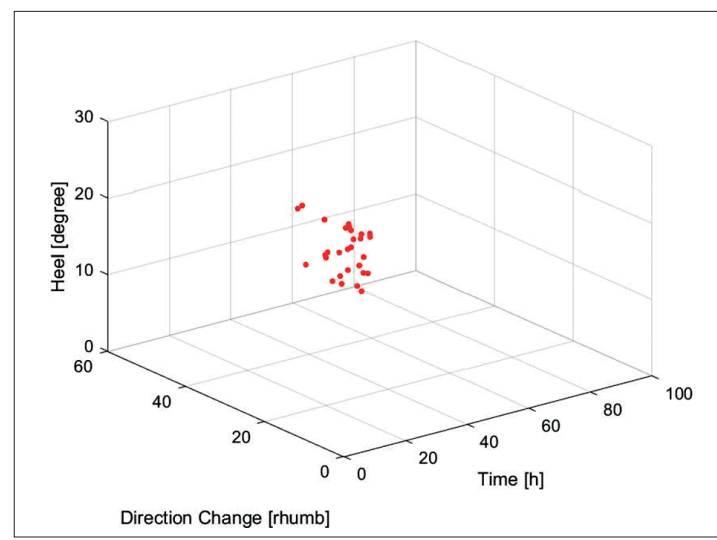

Fig. 9. Objective values of routes found in Scenario 3

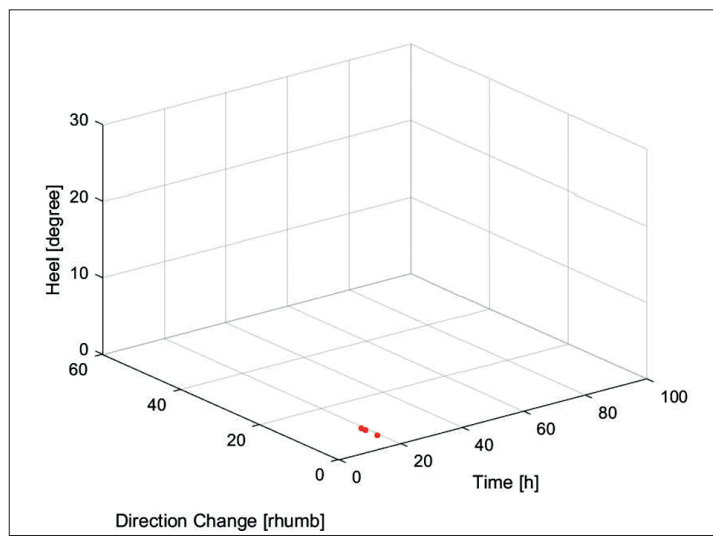

Fig. 11. Objective values of routes found in Scenario 4 


\section{SUMMARY AND CONCLUSIONS}

The article presents the multi-objective evolutionary method, which searches for the optimal routes of a sailboat navigating in changing wind conditions. The method uses an improved Strength Pareto Evolutionary Algorithm (SPEA 2), additionally enhanced by a preference-based $r$-dominance method, which is applied to improve the algorithm's performance and to focus on solutions which are compliant with the navigator's preferences. For this reason, the method is able to return the routes faster while making sure they are customised for a particular user. The routes obtained bypass obstacles in the form of land and choose the course with the most favourable position to the wind. The aim is to complete the route as quickly as possible while maintaining reasonable safety and comfort throughout the voyage. The method was tested in a series of computer simulations, whose examples are provided in the text. The simulation results vary, depending on the chosen scenario. First, the results differ for two and three optimisation objectives. By adding the third objective, namely, a sum of course changes, one can limit the number and size of turns, thus simplifying the task of following a route. The influence of weather conditions on the shape of the route is also visible. When encountering strong wind, the method returns a reduced set of solutions, because there are fewer acceptable ones to choose from. The resulting routes are then smoother because such shape translates to greater safety, comfort and efficiency of travel, and the smallest possible inclination. In general, the experiments confirmed that the chosen method can be an interesting alternative to the already existing ones and that the multi-objective approach can offer flexibility of the navigator's modelling within an acceptable computational time.

For now, the presented method suffers from some simplifications in the modelled environment. Among others, passenger comfort is modelled by the average angle of heel, whereas roll velocity and acceleration are often more uncomfortable in practice. Also, the method does not take into account such factors as the influence of waves or sea currents on the sailboat's speed. It is planned, however, to include these elements in upcoming research that will focus on utilising more advanced modelling to bring the method closer to marine reality. Once this is done, experiments with a real sailboat are envisaged. Other plans include handling the uncertainty of weather predictions by means of ensemble forecasts and refining the optimisation algorithm.

\section{REFERENCES}

1. Zitzler E, Laumanns M, Thiele L. SPEA2: Improving the Strength Pareto Evolutionary Algorithm. Evol Methods Des Optim Control with Appl to Ind Probl 2001:95-100. https:// doi.org/10.1.1.28.7571.

2. Ben Said L, Bechikh S, Ghedira K. The r-Dominance: A new dominance relation for interactive evolutionary multicriteria decision making. IEEE Trans Evol Comput 2010;14:801-18. https://doi.org/10.1109/TEVC.2010.2041060.

3. Jurdziński M. Podstawy Nawigacji Morskiej. Wydawncitwo Akademii Morskiej w Gdyni; 2003.

4. Brooks RL, Jasper NH, James RW. Statistics on wave heights and periods for the North Atlantic Ocean. Trans Am Geophys Union 1958;39:1064. https://doi.org/10.1029/ TR039i006p01064.

5. Wiśniewski B, Medyna P. Prognozowany zasięg pola sztormowego cyklonu tropikalnego jako domena rozmyta cyklonu. Zesz Nauk Akad Morskiej w Szczecinie 2004;nr 2:419-30.

6. Lisowski J. The Sensitivity of State Differential Game Vessel Traffic Model. Polish Marit Res 2016;23:14-8. https://doi. org/10.1515/pomr-2016-0015.

7. Spaans J. Windship Technology: Proceedings of the International Symposium on Windship Technology, Southampton, U.K., April 24-25, 1985., Elsevier Science; 1985, p. 385.

8. Motte R. On The Selection of Discrete Grid Systems for On-Board Microbased Weather Routeing. J Navig 1990;43:104-17.

9. Wiśniewski B. Programowanie tras statków na oceanach. Zesz Nauk / Akad Morska w Szczecinie 2012;29:164-73.

10. Singh Y, Sharma S, Sutton R, Hatton D. Optimal Path Planning of an Unmanned Surface Vehicle in a Real- Time Marine Environment using a Dijkstra Algorithm. Proc. 12th Int. Conf. Mar. Navig. Saf. Sea Transp., Gdynia: 2017, p. 399-402.

11. Neumann T. Method of Path Selection in the Graph - Case Study. TransNav, Int J Mar Navig Saf Sea Transp 2014;8:55762. https://doi.org/10.12716/1001.08.04.10.

12. Mannarini G, Coppini G, Oddo P, Pinardi N. A Prototype of Ship Routing Decision Support System for an Operational Oceanographic Service. TransNav, Int J Mar Navig Saf Sea Transp 2013;7:53-9. https://doi.org/10.12716/1001.07.01.06.

13. Zyczkowski M, Krata P, Szłapczyński R. Multi-objective weather routing of sailboats considering wave resistance. Polish Marit Res 2018;25. https://doi.org/10.2478/pomr-2018-0001.

14. Zyczkowski M, Szłapczyński R. Multi-Objective Weather Routing of Sailing Vessels. Polish Marit Res 2017;24. https:// doi.org/10.1515/pomr-2017-0130.

15. Życzkowski M. Sailing Vessel Routing Considering Safety Zone and Penalty Time for Altering Course. TransNav, Int J Mar Navig Saf Sea Transp 2017;11:49-54. https://doi. org/10.12716/1001.11.02.04. 
16. Naus K, Wąż M. The idea of using the $A^{\star}$ algorithm for route planning an unmanned vehicle "Edredon." Zesz Nauk / Akad Morska w Szczecinie 2013:143--147.

17. Goldberg A V. Point-to-Point Shortest Path Algorithms with Preprocessing. LNCS 4362 - SOFSEM 2007 Theory Pract. Comput. Sci., 2007.

18. Mostefa M-S. ScienceDirect The branch-and-bound method, genetic algorithm, and dynamic programming to determine a safe ship trajectory in fuzzy environment. Procedia Comput Sci 2014;35:348-57. https://doi.org/10.1016/j. procs.2014.08.115.

19. Walther L, Shetty S, Rizvanolli A, Jahn C. Comparing Two Optimization Approaches for Ship Weather Routing, Springer, Cham; 2018, p. 337-42. https://doi. org/10.1007/978-3-319-55702-1_45.

20. Vettor R, Szlapczynska J, Szlapczynski R, Tycholiz W, Soares CG. Towards improving optimised ship weather routing. Polish Marit Res 2020;27:60-9. https://doi.org/10.2478/ pomr-2020-0007.

21. Ni S, Liu Z, Cai Y, Wang X. Modelling of Ship's Trajectory Planning in Collision Situations by Hybrid Genetic Algorithm. Polish Marit Res 2018;25:14-25. https://doi.org/https://doi. org/10.2478/pomr-2018-0092.

22. Lazarowska A. Multi-criteria ACO-based Algorithm for Ship's Trajectory Planning. TransNav, Int J Mar Navig Saf Sea Transp 2017;11:31-6. https://doi.org/10.12716/1001.11.01.02.

23. Lisowski J. Optimization Methods in Maritime Transport and Logistics. Polish Marit Res 2018;25:30-8. https://doi. org/10.2478/pomr-2018-0129.

24. Tsou M-C, Cheng H-C. An Ant Colony Algorithm for efficient ship routing. Polish Marit Res 2013;20:28-38. https://doi. org/10.2478/pomr-2013-0032.

25. Liu Y, Bucknall R. Path planning algorithm for unmanned surface vehicle formations in a practical maritime environment. Ocean Eng 2015;97:126-44. https://doi.org/10.1016/j. oceaneng.2015.01.008.

26. Szlapczynski R, Krata P. Determining and visualizing safe motion parameters of a ship navigating in severe weather conditions. Ocean Eng 2018;158. https://doi.org/10.1016/j. oceaneng.2018.03.092.

27. Życzkowski M, Szłapczyńska J, Szłapczyński R. Review of Weather Forecast Services for Ship Routing Purposes. Polish Marit Res 2019;26:80-9. https://doi.org/https://doi. org/10.2478/pomr-2019-0069.

28. Zhao J, Fan J. A Ship Network Dynamic Routing Algorithm
Based on Vector Network. Polish Marit Res 2018;25:62-8. https://doi.org/https://doi.org/10.2478/pomr-2018-0075.

29. Krata P, Szlapczynska J. Ship weather routing optimization with dynamic constraints based on reliable synchronous roll prediction. Ocean Eng 2018;150:124-37. https://doi. org/10.1016/j.oceaneng.2017.12.049.

30. Pérez Arribas FL, López Piñeiro A. Seasickness prediction in passenger ships at the design stage. Ocean Eng 2007;34:208692. https://doi.org/10.1016/j.oceaneng.2007.02.009.

31. Wang HB, Li XG, Li PF, Veremey EI, Sotnikova M V. Application of Real-Coded Genetic Algorithm in Ship Weather Routing. J Navig 2018;71:989-1010. https://doi.org/10.1017/ S0373463318000048.

32. Bechikh S, Kessentini M, Said L Ben, Ghédira K. Preference Incorporation in Evolutionary Multiobjective Optimization: A Survey of the State-of-the-Art. Adv Comput 2015;98:141207. https://doi.org/10.1016/bs.adcom.2015.03.001.

33. Sindhya K, Miettinen K, Deb K. A hybrid framework for evolutionary multi-objective optimization. IEEE Trans Evol Comput 2013;17:495-511. https://doi.org/10.1109/ TEVC.2012.2204403.

34. Deb K, Jain H. An evolutionary many-objective optimization algorithm using reference-point-based nondominated sorting approach, Part I: Solving problems with box constraints. IEEE Trans Evol Comput 2014;18:577-601. https://doi. org/10.1109/TEVC.2013.2281535.

35. Ishibuchi H, Imada R, Setoguchi Y, Nojima Y. Reference Point Specification in Inverted Generational Distance for Triangular Linear Pareto Front. IEEE Trans Evol Comput 2018;22:96175. https://doi.org/10.1109/TEVC.2017.2776226.

36. Jaimes AL, Montaño AA, Coello CAC. Preference incorporation to solve many-objective airfoil design problems. 2011 IEEE Congr Evol Comput CEC 2011 2011:1605-12. https://doi.org/10.1109/CEC.2011.5949807.

37. Sielicka MW, Stateczny A. Clustering Bathymetric Data for Electronic Navigational Charts. J Navig 2016;69:1143-53. https://doi.org/10.1017/S0373463316000035.. 


\section{CONTACT WITH THE AUTHORS}

\section{Ewa Sobecka}

e-mail:ewa.warsinska@pg.edu.pl

\section{Rafał Szłapczyński}

e-mail: rafal.szlapczynski@pg.edu.pl

Marcin Życzkowski

e-mail:marzyczk@pg.edu.pl

Gdańsk University of Technology

11/12 Gabriela Narutowicza Street 80-233 Gdańsk

Poland 